\title{
The Functional, Metabolic, and Anabolic Responses to Exercise Training in Renal Transplant and Hemodialysis Patients
}

Citation for published version (APA):

van den Ham, E. C. H., Kooman, J. P., Schols, A. M., Nieman, F. H. M., Does, J. D., Akkermans, M. A., Janssen, P. P., Gosker, H. R., Ward, K. A., Macdonald, J. H., Christiaans, M. H., Leunissen, K. M., \& van Hooff, J. P. (2007). The Functional, Metabolic, and Anabolic Responses to Exercise Training in Renal Transplant and Hemodialysis Patients. Transplantation, 83(8), 1059-1068.

https://doi.org/10.1097/01.tp.0000259552.55689.fd

Document status and date:

Published: 01/01/2007

DOI:

10.1097/01.tp.0000259552.55689.fd

Document Version:

Publisher's PDF, also known as Version of record

Document license:

Taverne

Please check the document version of this publication:

- A submitted manuscript is the version of the article upon submission and before peer-review. There can be important differences between the submitted version and the official published version of record.

People interested in the research are advised to contact the author for the final version of the publication, or visit the DOI to the publisher's website.

- The final author version and the galley proof are versions of the publication after peer review.

- The final published version features the final layout of the paper including the volume, issue and page numbers.

Link to publication

\footnotetext{
General rights rights.

- You may freely distribute the URL identifying the publication in the public portal. please follow below link for the End User Agreement:

www.umlib.nl/taverne-license

Take down policy

If you believe that this document breaches copyright please contact us at:

repository@maastrichtuniversity.nl

providing details and we will investigate your claim.
}

Copyright and moral rights for the publications made accessible in the public portal are retained by the authors and/or other copyright owners and it is a condition of accessing publications that users recognise and abide by the legal requirements associated with these

- Users may download and print one copy of any publication from the public portal for the purpose of private study or research.

- You may not further distribute the material or use it for any profit-making activity or commercial gain

If the publication is distributed under the terms of Article $25 \mathrm{fa}$ of the Dutch Copyright Act, indicated by the "Taverne" license above, 


\title{
The Functional, Metabolic, and Anabolic Responses to Exercise Training in Renal Transplant and Hemodialysis Patients
}

\author{
Eugénie C. H. van den Ham, ${ }^{1,6}$ Jeroen P. Kooman, ${ }^{1}$ Annemie M. W. J. Schols, ${ }^{2}$ Fred H. M. Nieman, ${ }^{3}$ \\ Joan D. Does, ${ }^{4}$ Marco A. Akkermans, ${ }^{4}$ Paul P. Janssen, ${ }^{4}$ Harry R. Gosker, ${ }^{2}$ Kimberly A. Ward, ${ }^{2}$ \\ Jamie H. MacDonald, ${ }^{5}$ Maarten H. L. Christiaans, ${ }^{1}$ Karel M. L. Leunissen, ${ }^{1}$ and Johannes P. van Hooff
}

\begin{abstract}
Background. Exercise intolerance is common in hemodialysis (HD) and renal transplant (RTx) patients and is related to muscle weakness. Its pathogenesis may vary between these groups leading to a different response to exercise. The aim of the study was to compare intrinsic muscular parameters between HD and RTx patients and controls, and to assess the response to exercise training on exercise capacity and muscular structure and function in these groups.

Methods. Quadriceps function (isokinetic dynamometry), body composition (dual-energy x-ray absorptiometry), and vastus lateralis muscle biopsies were analyzed before and after a 12-week lasting training-program in $35 \mathrm{RTx}$ patients, 16 HD patients, and 21 healthy controls.

Results. At baseline, myosin heavy chain (MyHC) isoform composition and enzyme activities were not different between the groups. $\mathrm{VO}_{2}$ peak and muscle strength improved significantly and comparably over the training-period in RTx, HD patients and controls $\left(\mathrm{p}_{\text {time }}<0.05\right)$. The proportion of MyHC type I isoforms decreased $\left(\mathrm{p}_{\text {time }}<0.001\right)$ and type IIa MyHC isoforms increased $\left(\mathrm{p}_{\text {time }}<0.05\right)$. The 3-hydroxyacyl-CoA-dehydrogenase activity increased $\left(\mathrm{p}_{\text {time }}=0.052\right)$. Intrinsic muscular changes were not significantly different between groups. In the HD group, changes in lean body mass were significantly related to changes in muscle insulin-like growth factor (IGF)-II and IGF binding protein-3.

Conclusions. Abnormalities in metabolic enzyme activities or muscle fiber redistribution do not appear to be involved in muscle dysfunction in RTx and HD patients. Exercise training has comparable beneficial effects on functional and intrinsic muscular parameters in RTx patients, HD patients, and controls. In HD patients, the anabolic response to exercise training is related to changes in the muscle IGF system.
\end{abstract}

Keywords: Exercise training, Exercise capacity and skeletal muscle strength, Muscle biopsy, Muscle fiber distribution, Enzyme activity, Insulin-like growth factor system, Renal transplant patients, Hemodialysis patients.

(Transplantation 2007;83: 1059-1068)

$\mathrm{I}_{\mathrm{n}}^{\mathrm{n}}$ patients with end-stage renal failure (ESRF), physical functioning is severely impaired (1). Although in some studies an improvement in exercise capacity after renal transplantation has been observed (2), we recently showed that exercise capacity was equally reduced in stable renal transplant (RTx) patients and hemodialysis (HD) patients on the transplant waiting list (3). Moreover, we found skeletal muscle strength and physical activity level to be important determinants of exercise capacity in RTx patients, whereas low

This study was supported by a grant from the Dutch Kidney Foundation, Bussum, the Netherlands.

${ }^{1}$ Department of Internal Medicine, University Hospital Maastricht, Maastricht, the Netherlands.

${ }^{2}$ Department of Respiratory Medicine, University Hospital Maastricht, Maastricht, the Netherlands.

${ }^{3}$ Department of Clinical Epidemiology and Medical Technology Assessment, University Hospital Maastricht, Maastricht, the Netherlands.

${ }^{4}$ Center for Integrated Rehabilitation of Organ Failure, Horn, the Netherlands.

${ }^{5}$ School of Sport, Health, and Exercise Sciences, University of Wales-Bangor, Bangor, Wales.

${ }^{6}$ Address correspondence to: Eugénie C.H. van den Ham, Ph.D., Department of Internal Medicine, Division Nephrology, University Hospital Maastricht, P.O. Box 5800, 6202 AZ Maastricht, the Netherlands.

E-mail: evha@groupwise.azm.nl

Received 3 November 2006. Revision requested 29 November 2006.

Accepted 28 January 2007.

Copyright $\odot 2007$ by Lippincott Williams \& Wilkins

ISSN 0041-1337/07/8308-1059

DOI: 10.1097/01.tp.0000259552.55689.fd maintenance doses of corticosteroids did not appear to affect exercise capacity (3).

Skeletal muscle function depends not only on muscle mass, but also on muscular structure and metabolism. Besides disuse of muscles due to a lack of physical activity, disease-specific factors such as the use of corticosteroids $(4-7)$ and a reduced renal function could influence muscular mass (3), structure, and metabolism in RTx patients. In HD patients, these parameters might be further impaired by malnutrition, inflammation, and oxidative stress $(8-10)$. Moreover, the insulin-like growth factor (IGF) system - a key endocrine regulator of muscle mass and metabolism (11) is altered in $\mathrm{HD}$ patients $(12,13)$. Although there are various data on intrinsic abnormalities in muscle structure and metabolism in RTx and HD patients $(4,5,7,12-15)$, there are no direct comparisons on this subject between RTx and HD patients and controls.

Muscular fibers are basically divided into type I, slowtwitch, oxidative fibers, and type II fast-twitch, glycolytic fibers. Type II fibers can be further subdivided into type IIx fibers that are exclusively glycolytic and IIa fibers, which drive on both glycolytic and oxidative metabolic processes (16). In general, physical inactivity will predominantly lead to a shift from type I to type II fibers. Malnutrition, chronic inflammation, and oxidative stress are predominantly associated with abnormalities in type II glycolytic muscular fibers $(16,17)$. Although corticosteroids induce skeletal muscle atrophy (the 
fast glycolytic fibers most affected) $(4,7)$, the first hypothesis of the study is that in RTx patients predominantly type I fibers will be affected due to the predominant effects of disuse, leading to a relative shift to type II fibers, whereas in HD patients a relative shift to type I fibers is expected.

Previous studies found a reduced muscular oxidative capacity in RTx and HD patients (18-20). Although the factors mentioned in the previous paragraph may also be involved, the reasons for this phenomenon are not yet clear, nor have comparisons between both groups been performed. The second hypothesis of the study is that the enzyme activity of oxidative enzymes is reduced in RTx patients compared to controls, and will be further lowered in HD patients.

Assuming that disuse is the major factor in the reduced exercise tolerance and muscle strength of RTx patients, exercise training is of great potential benefit for this patient population. Indeed, various studies have found improvements in muscular strength and exercise capacity after a training program in RTx and HD patients $(18,19,21-29)$. The response to exercise training has never been compared between RTx and HD patients and controls. Due to the possible role of disease specific factors in the pathogenesis of muscle dysfunction and exercise intolerance in renal patients, we hypothesize that the functional response to exercise training is less in RTx patients compared to controls, and further lowered in HD patients.

Exercise training may also lead to an increase in muscle mass. In the anabolic response, the muscular IGF system, which plays a primary role in controlling skeletal muscle protein synthesis and breakdown, may be of pivotal importance (11). In HD patients, reduced muscle IGF-I protein and mRNA levels and resistance to the IGF effects in skeletal muscle have been observed $(12,13)$. In RTx patients, corticosteroids can reduce pituitary growth hormone production and the local production of IGF-I (30). However, the muscular IGF system has not been studied in RTx patients so far, nor have the relation between the anabolic response to exercise training and changes in the mIGF system been assessed in renal patients.

The first aim of the study was to compare muscular fiber distribution and muscular enzyme activities between RTx patients, HD patients and controls. The second aim was to compare the functional response, as well as changes in intrinsic muscular parameters after exercise training between these three groups, and to assess the relationship between changes in muscular IGF system and the anabolic response to exercise training.

\section{PATIENTS AND METHODS}

\section{Subjects}

Thirty-five RTx patients, $16 \mathrm{HD}$ patients and 21 agematched, untrained healthy subjects, were included in the study. All patients were in clinically stable condition. In RTx patients, transplantation occurred at least 6 months before start of the study. HD patients had been treated with hemodialysis for at least 3 months, were receiving renal replacement therapy three times weekly $(\mathrm{Kt} / \mathrm{V}$ at least 1.2 ; use of synthetic or modified cellulose membranes), and were on the waiting list for renal transplantation. Exclusion criteria were hemoglobin $<10.2 \mathrm{~g} / \mathrm{dL}$, diabetes mellitus (because of possible interfering effects on muscle biopsy parameters), history of malignancy (except nonmetastatic basal or squamous cell carcinoma), history of heart disease, organ transplant other than kidney, use of corticosteroids for other reasons than kidney transplantation, and musculoskeletal problems.

Thirty-three RTx patients, 14 HD patients, and 18 controls fully completed the training and had complete registration of baseline and follow-up measurements (except for biopsies). Reasons for dropout were hospitalization for cataract surgery (1) and personal problems (1) in the RTx group, hospitalization for pneumonia (1) and refusal to continue training (1) in the HD group, and electrocardiogram abnormalities during the baseline cycle-test (2) and suffering from overstrain (1) in controls. Subject characteristics are given in Table 1.

Patients who were eligible were asked to participate in the study at the outpatient clinic of our hospital and six HD departments in our district. Controls were either patient's partners or volunteers recruited by advertisement. Written informed consent was obtained from each subject prior to participation. The Ethical Committee of the Maastricht University Hospital approved the study.

\section{Study Design}

The design of the training study can be described as a natural groups cohort study in which differences between a "before" state without stimulus are compared to the stimulus-induced "after" state in the three groups as a whole, while at the same time response differences in time are compared between the three groups. All subjects underwent extensive medical examination and baseline measurements before training was started; renal patients also underwent exercise electrocardiography. Exercise capacity and muscle function were measured again after 6 weeks of training; if necessary, the training intensity was adjusted to maintain a constant relative training intensity. All baseline measurements were repeated after completion of the training program.

In HD patients, measurements (except blood sampling) were performed each time on the first nondialysis day after HD treatment. Training was performed on nondialysis days.

\section{Exercise Capacity and Muscle Function}

Maximal exercise capacity was measured by symptomlimited graded cycle-ergometry, as described previously (3). In short, a progressively increasing work rate test was started to determine peak work rate (Wpeak) and peak oxygen uptake $\left(\mathrm{VO}_{2}\right.$ peak). The work rate was increased with 10-25 $\mathrm{W} / \mathrm{min}$ in patients and with $10-30 \mathrm{~W} / \mathrm{min}$ in controls, so that the length of the test was comparable for all subjects. $\mathrm{VO}_{2}$ peak was defined as the highest recorded oxygen uptake at peak exercise and was expressed in absolute terms and relative to body weight (BW) and muscle mass.

Isokinetic quadriceps strength (dominant leg) was measured using a Cybex II plus dynamometer (Lumex Inc.), as described previously (3). Maximal strength was defined as the highest peak torque of fifteen consecutive maximal contractions (angle velocity 90 degrees/sec) and was expressed in absolute terms and relative to muscle mass of the legs. Moreover, maximal strength of different muscle groups in the arms, legs, abdomen, back, and chest was measured with specific fitness equipment. 


\section{TABLE 1. Subject characteristics at baseline}

\section{Renal transplant patients}

$\mathrm{n}$

Age (years)

Sex (male/female)

Weight $(\mathrm{kg})$

Body mass index $\left(\mathrm{kg} / \mathrm{m}^{2}\right)$

Time after transplantation (months)

Time on dialysis prior to transplantation (months)

Time on hemodialysis (months)

Creatinine clearance $(\mathrm{mL} / \mathrm{min})^{a}$

Creatinine clearance $(\mathrm{mL} / \mathrm{min})^{b}$

Smoking

Blood parameters

Hemoglobin (g/dL)

Creatinine $(\mu \mathrm{mol} / \mathrm{L})^{c}$

Urea (mmol/L)

Albumin (g/L)

Glucose $(\mathrm{mmol} / \mathrm{L})^{c}$

C-reactive protein $(\mathrm{mg} / \mathrm{L})$

Sodium ( $\mathrm{mmol} / \mathrm{L})$

Potassium $(\mu \mathrm{mol} / \mathrm{L})$

Calcium $(\mathrm{mmol} / \mathrm{L})$

Phosphate $(\mathrm{mmol} / \mathrm{L})$

Parathyroid hormone ( $\mathrm{mmol} / \mathrm{L})$

Causes of renal failure

Chronic glomerulonephritis

Pyelonephritis/interstitial nephritis

Nephrosclerosis

Polycystic kidney disease

Congenital sphincter sclerosis

Unknown

Medication use

Steroid-based immunosuppression ${ }^{d}$

Steroid-free immunosuppression ${ }^{e}$

Beta-blockers

Erythropoietin

\section{3}

$52.1 \pm 10.3$

$18 / 15$

$74.6 \pm 15.1$

$25.7 \pm 3.9$

$86.2 \pm 82.4^{f}$

$24.9 \pm 20.5^{g}$

$-$

$59.7 \pm 16.3^{m}$

$62.9 \pm 18.7$

4 (12.1\%)

$13.8 \pm 1.5$

$136 \pm 52^{m}$

$8.8 \pm 4.1^{j}$

$41.6 \pm 3.3$

$5.8 \pm 0.9$

$4.0 \pm 3.4$

$139.5 \pm 1.7$

$4.5 \pm 0.5$

$2.43 \pm 0.16$

$1.08 \pm 0.32$

9.9 \pm 4.5

$16(48.5 \%)$

$3(9.1 \%)$

$3(9.1 \%)$

$7(21.2 \%)$

$1(3.0 \%)$

$3(9.1 \%)$

$16(48.6 \%)$

$17(51.4 \%)$

$23(69.7 \%)$
Hemodialysis patients

Controls

18

$48.4+11.9$

$9 / 5$

$55.7 \pm 10.0$

$9 / 9$

$67.9 \pm 14.1^{i}$

$79.6 \pm 12.3$

$23.1 \pm 3.5^{j}$

$26.5 \pm 2.9$

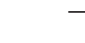

$22.4 \pm 15.7^{h}$

-

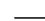

$5(35.7 \%)$

$12.2 \pm 1.2^{k, l}$

$1012 \pm 378^{m, o}$

$23.8 \pm 6.8^{j, l}$

$41.0 \pm 3.9$

$5.5 \pm 1.1$

$6.4 \pm 10.2$

$138.0 \pm 2.4^{n}$

$4.9 \pm 0.7^{n}$

$2.32 \pm 0.20^{p}$

$1.81 \pm 0.60^{\circ}$

$15.8 \pm 10.1^{q}$

$6(42.9 \%)$

$1(7.1 \%)$

2 (14.3\%)

$3(21.4 \%)$

$2(14.3 \%)$

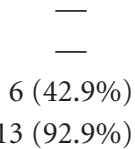

-

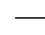

$-$

$103.0 \pm 22.2$

$4(22.2 \%)$

$14.3 \pm 1.3$

$75 \pm 12$

$4.5 \pm 0.9$

$41.9 \pm 2.3$

$5.5 \pm 0.7$

$3.5 \pm 3.4$

-

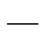

$-$

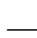

$-$

Data are given as mean \pm SD or as $\mathrm{n}(\%)$.

a Calculated by Cockcroft and Gault formula.

${ }^{b}$ Calculated from 24-hour urine volume and creatinine levels in plasma and 24-hour urine.

${ }^{c}$ Data not normally distributed.

${ }^{d}$ Prednisolone (5-10 mg/day) in combination with FK-506 or cyclosporine A.

${ }^{e}$ FK-506 or cyclosporine A monotherapy.

${ }^{f}$ Median time after RTx was 46.9 (range 8.7-289.3) months.

${ }^{g}$ Median time on dialysis prior to RTx $(\mathrm{n}=31$; two patients pre-emptive RTx) was 19.6 (range 0.7-84.0) months.

${ }^{h}$ Median time on hemodialysis was 17.1 (range 3.0-56.3) months.

${ }^{i} P=0.059$ versus controls, corrected for sex.

${ }^{j} P<0.05$ versus controls, corrected for sex.

${ }^{k} P<0.01$ versus controls, corrected for sex.

${ }^{l} P<0.01$ versus RTx, corrected for sex.

${ }^{m} P<0.01$ versus controls.

${ }^{n} P<0.05$ versus RTx.

${ }^{o} P<0.01$ versus RTx.

${ }^{P} P=0.058$ versus RTx.

${ }^{q} P=0.056$ versus RTx. 


\section{Body Composition}

Lean body mass (LBM) was measured by dual-energy $\mathrm{x}$-ray absorptiometry (DEXA; DPX-L, Lunar Radiation Corp., Madison, WI) (3). LBM was used as an estimate of muscle mass. The extracellular water (ECW) volume was determined by multifrequency bioelectrical impedance analysis (4000B, Xitron Technologies Inc, San Diego, CA).

\section{Blood Parameters}

Blood samples were taken in patients and controls (in HD patients before start of HD treatment). All blood tests except C-reactive protein (high-sensitivity particle-enhanced immunonephelometry [31]) were performed according to standard laboratory procedures.

\section{Muscle Fiber Distribution, Metabolic Profile, and IGF System}

Postabsorptive muscle biopsies (vastus lateralis) were obtained under local anesthesia by the needle biopsy technique (32). Samples were immediately frozen in liquid nitrogen and stored at $-80^{\circ} \mathrm{C}$ until further processing. Enzyme activity assays of glycogen phosphorylase (GlyP), phosphofructokinase (PFK), citrate synthase (CS), and 3-hydroxyacyl-CoA-dehydrogenase (HAD) (33-36) and MyHC isoform analyses (37) were performed as earlier described by Gosker (38). MyHC isoforms I, IIa, and IIx were expressed proportionally to each other.

Muscle insulin-like growth factor-I, -II, and binding protein-3 concentrations (mIGF-I, mIGF-II, mIGFBP-3) were measured by in house specific radioimmunoassays and fragmentation of mIGFBP-3 by Western immunoblotting as previously described by MacDonald (12). Based on the pixel density of the three revealed bands $(43-46 \mathrm{kDa}$ doublet and $30 \mathrm{kDa}$ fragment), percentage of fragmented IGFBP-3 was calculated.

\section{Exercise Training Program}

The standardized 12-weeks lasting training program consisted of both endurance and strength training (two 2-hour supervised sessions per week). Each session consisted of endurance training (cycle-ergometry and treadmill walking), dynamic strength training of specific muscle groups (fitness equipment), and alternating swimming or gymnastics. The strength training was composed of both specific resistance training (a small number of repetitions, relatively high load) and strength-endurance training (a large number of repetitions, relatively low load). Training-sessions were performed in mixed groups $(n \approx 10)$ of patients and controls.

An individual (standardized) program based on the results of the cycle- and strength tests at baseline was developed for each subject. In the first 6 weeks of the training program, the intensity of the cycle-training gradually increased from $50 \%$ to $70 \%$ of Wpeak at baseline, the intensity of the specific resistance training from $2 \times 8$ repetitions at $50 \%$ to $3 \times 10$ repetitions at $60 \%$ of the maximal strength at baseline $\left(\operatorname{Pmax}_{\text {baseline }}\right)$, and the intensity of the strength-endurance training from $1 \times 30$ repetitions at $25 \%$ to $3 \times 30$ repetitions at $35 \%$ of Pmax $_{\text {baseline. In weeks }} 7$ to 12 , the intensity of the cycle-training increased from $60 \%$ of Wpeak measured after 6 weeks of training $\left(\mathrm{Wpeak}_{\text {six }}\right.$ ) to finally $70 \%$ of $\mathrm{Wpeak}_{\text {six }}$, the intensity of the resistance training from $2 \times 10$ repetitions at $50 \%$ to $3 \times 10$ repetitions at $60 \%$ of $\operatorname{Pmax}_{\text {six }}$, and the intensity of the strength-endurance training from $1 \times 30$ repetitions at $25 \%$ to $3 \times 30$ repetitions at $35 \%$ of $\operatorname{Pmax}_{\text {six }}$. Treadmill walking all the time was performed just below the symptomlimited rate, at which heart rates were comparable to those reached during cycle-training.

\section{Statistics}

\section{Patient Characteristics and Baseline Comparisons}

Kruskal-Wallis tests were used to compare not normally distributed variables between the groups. Approximately normally distributed variables were compared by one-way analysis of variance (ANOVA) with correction for pairwise multiple comparisons via post-hoc Bonferroni or Dunnett-T3 tests. Twoway ANOVA was used to determine sex-corrected differences. Differences in discrete variables were assessed by log-likelihood chi-square tests.

\section{Effects of Training}

Statistical analysis was performed by repeated measures analysis of (co)variance. In this way, the effects of the factors "time," "group," and of the interaction term "time by group" could be determined. A significant "time" factor can be interpreted such that the parameters, averaged over all groups, significantly change over the training period; a significant "time by group" interaction points to differences in the withintime changes of these parameters between the three groups. If a significant overall "time by group" interaction was found, separate paired $t$-tests were performed to determine changes over time for each group. Data are expressed as means \pm SD, unless indicated otherwise. Statistical analysis was performed by SPSS for Windows, version 12.0. $P$ values $<0.05$ were considered statistically significant.

\section{Sample Size}

The main outcome parameter was the change in $\mathrm{VO}_{2}$ peak during the training period. We estimated the increase in $\mathrm{VO}_{2}$ peak after training to be approximately 12.5 $\mathrm{mL} / \mathrm{min} / \mathrm{kg}$ in controls, $8 \mathrm{~mL} / \mathrm{min} / \mathrm{kg}$ in RTx patients, and 3 $\mathrm{mL} / \mathrm{min} / \mathrm{kg}$ in HD patients $(18,39)$. For an estimated SD of $4.3 \mathrm{~mL} / \mathrm{min} / \mathrm{kg}$, a two-tailed $\alpha$ of 0.025 , and power of $0.80,14$ subjects per group are required. Eighteen subjects per group would adjust for an assumed 25\% dropout (noncompliance, transplantation, medical complications).

\section{RESULTS}

\section{Exercise Capacity, Muscle Function, and Body Composition}

Baseline and posttraining results regarding exercise capacity, muscle function, and body composition are given in Table 2. Baseline between-groups comparisons of these parameters are described elsewhere (3). With regard to the response to exercise training, Wpeak of patients and controls improved over the training period $\left(\mathrm{p}_{\text {time }}<0.001\right) . \mathrm{VO}_{2}$ peak (absolute and adjusted for BW and LBM) also increased ( $\left.p_{\text {time }} \leq 0.01\right)$, just like the respiratory coefficient $(R E R)$ at Wpeak $\left(\mathrm{p}_{\text {time }}<0.05\right)$. There were no significant differences in 
TABLE 2. Changes in exercise capacity and skeletal muscle strength (adjusted for age and sex) and changes in body composition (adjusted for age) in the renal transplant (RTx), hemodialysis (HD), and control (CON) groups ${ }^{a}$

\begin{tabular}{|c|c|c|c|c|}
\hline & RTx & HD & $\mathrm{CON}$ & F-ratio ${ }^{b}$ \\
\hline \multicolumn{5}{|l|}{ Exercise capacity } \\
\hline Baseline & $135 \pm 50$ & $118 \pm 54$ & $179 \pm 57$ & \\
\hline Posttraining & $162 \pm 60$ & $145 \pm 66$ & $210 \pm 68$ & $\mathrm{~F}_{(2,59)}=1.245 ; P=0.295$ \\
\hline \multicolumn{5}{|l|}{$\mathrm{VO}_{2}$ peak $(\mathrm{mL} / \mathrm{min})$} \\
\hline Posttraining & $1747 \pm 515$ & $1668 \pm 702$ & $2279 \pm 876$ & $\mathrm{~F}_{(2,58)}=0.261 ; P=0.771$ \\
\hline \multicolumn{5}{|c|}{$\mathrm{VO}_{2}$ peak $(\mathrm{mL} / \mathrm{min} / \mathrm{kg} \mathrm{BW})$} \\
\hline Baseline & $21.6 \pm 6.3$ & $21.8 \pm 7.8$ & $27.5 \pm 7.6$ & \\
\hline Posttraining & $23.8 \pm 6.1$ & $23.9 \pm 7.4$ & $28.0 \pm 8.2$ & $\mathrm{~F}_{(2,58)}=0.870 ; P=0.425$ \\
\hline \multicolumn{5}{|c|}{$\mathrm{VO}_{2}$ peak $(\mathrm{ml} / \mathrm{min} / \mathrm{kg} \mathrm{LBM})$} \\
\hline \multicolumn{5}{|l|}{ RER peak } \\
\hline Posttraining & $1.19 \pm 0.10$ & $1.21 \pm 0.10$ & $1.15 \pm 0.08$ & $\mathrm{~F}_{(2,58)}=1.499 ; P=0.232$ \\
\hline \multicolumn{5}{|c|}{ Skeletal muscle strength } \\
\hline \multicolumn{5}{|l|}{ Quadriceps (nM) } \\
\hline Baseline & $89.6 \pm 31.2$ & $86.4 \pm 30.7$ & $122.6 \pm 34.7$ & \\
\hline Posttraining & $98.8 \pm 33.2$ & $89.0 \pm 34.1$ & $133.6 \pm 42.0$ & $\mathrm{~F}_{(2,52)}=1.293 ; P=0.283$ \\
\hline \multicolumn{5}{|c|}{ Quadriceps (nM/kg LM legs) } \\
\hline Baseline & $5.7 \pm 1.3$ & $5.6 \pm 1.2$ & $7.0 \pm 1.1$ & \\
\hline Posttraining & $6.3 \pm 1.2$ & $5.7 \pm 1.5$ & $7.4 \pm 1.2$ & $\mathrm{~F}_{(2,52)}=1.057 ; P=0.355$ \\
\hline \multicolumn{5}{|l|}{ Chest $(\mathrm{kg})^{c}$} \\
\hline Baseline & $33.6 \pm 13.7$ & $31.7 \pm 14.6$ & $39.3 \pm 14.6$ & \\
\hline Baseline & $54.0 \pm 8.2$ & $53.8 \pm 8.6$ & $62.2 \pm 3.3$ & \\
\hline Posttraining & $54.2 \pm 8.2$ & $53.7 \pm 8.7$ & $64.5 \pm 4.4^{f}$ & $\mathrm{~F}_{(2,32)}=4.072 ; P=0.027$ \\
\hline Females (n) & 15 & 5 & 9 & \\
\hline \multicolumn{5}{|l|}{ BW (kg) } \\
\hline Baseline & $70.7 \pm 18.9$ & $56.9 \pm 9.5$ & $72.3 \pm 12.6$ & \\
\hline Posttraining & $70.7 \pm 19.4$ & $57.8 \pm 9.8$ & $72.1 \pm 12.3$ & $\mathrm{~F}_{(2,25)}=1.019 ; P=0.375$ \\
\hline \multicolumn{5}{|l|}{$\operatorname{LBM}(\mathrm{kg})$} \\
\hline Baseline & $40.7 \pm 6.2$ & $34.9 \pm 5.9$ & $41.1 \pm 6.7$ & \\
\hline Posttraining & $39.9 \pm 6.8$ & $36.0 \pm 6.1$ & $41.5 \pm 6.6$ & $\mathrm{~F}_{(2,25)}=2.871 ; P=0.075$ \\
\hline
\end{tabular}

Data given as mean $\pm S D$.

${ }^{a}$ Results of regression analysis, adjusted for age and sex or adjusted for age.

${ }^{b}$ F-ratio of the effects of "group".

${ }^{c}$ Pectoralis major and deltoideus anterior.

${ }^{d} P<0.05$ compared to baseline.

${ }^{e} P=0.058$ compared to baseline.

${ }^{f} P<0.01$ compared to baseline.

$\mathrm{W}$, work load; $\mathrm{VO}_{2}$, oxygen uptake; $\mathrm{BW}$, body weight; LBM, lean body mass; RER, respiratory exchange ratio; LM, lean mass. 
changes of Wpeak, $\mathrm{VO}_{2}$ peak, and RER over time between the

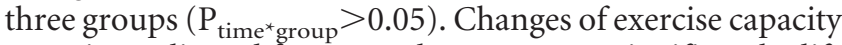
over time adjusted for age and sex were not significantly different either (Table 2).

Quadriceps strength (absolute and adjusted for lean mass legs) increased significantly over time in patients and controls ( $\mathrm{p}_{\text {time }}<0.001$ and $\mathrm{p}_{\text {time }}<0.05$, respectively). The change of quadriceps strength over time was not significantly different between the groups $\left(\mathrm{P}_{\text {time }}{ }_{\text {group }}>0.05\right)$, even if corrected for age and sex (Table 2).

The maximal strength of the other measured muscle groups (results not all shown) also improved significantly in patients and controls $\left(\mathrm{p}_{\text {time }}<0.05\right)$. Changes in strength of these muscle groups (both nonadjusted $\left[\mathrm{P}_{\text {time }}{ }^{*}\right.$ group $\left.>0.05\right]$ and adjusted for age and gender [Table 2]) were not significantly different between the groups.

Because of a significant interaction between sex and group in the statistical analysis, separate analyses were performed for males and females. In males, body weight (BW) did not change significantly over time in patients and controls $\left(\mathrm{p}_{\text {time }}=0.248\right)$, but the LBM increased significantly $\left(p_{\text {time }}=0.028\right)$. Changes in BW and LBM over time were significantly different among the groups $\left(\mathrm{p}_{\text {time }} \mathrm{e}_{\text {group }}=0.001\right.$ and $\mathrm{p}_{\text {time }}{ }^{* \text { group }}=0.020$, respectively), also after adjustment for age $\left(\mathrm{p}_{\text {group }}<0.001\right.$ and $\mathrm{p}_{\text {group }}=0.027$, respectively; Table 2$)$. Controls had significantly higher gains of BW and LBM than RTx $(P=0.001$ and $P<0.05$, respectively) or HD patients $(P<0.001$ and $P<0.05$, respectively), but changes in BW and LBM were not significantly different between the patient groups. In females, BW and LBM did not significantly change over time in patients and controls, neither differences between the groups were observed. Both in males and females, ECW did not change significantly over time. In-time changes in ECW were also not significantly different between the groups.
In RTx patients, the use of corticosteroids had no significant interaction with the response to training.

\section{Muscle Fiber Distribution and Metabolic Profile}

At baseline, muscle biopsy specimens were available in 25 RTx patients, $14 \mathrm{HD}$ patients, and 19 controls. In $20 \mathrm{RTx}$ patients, $10 \mathrm{HD}$ patients and 12 controls, muscle biopsy specimens were successfully obtained before and after the trainingprogram. In the RTx group, reasons for missing baseline samples were contraindications (6), patient refusal (1), and unsuccessful sampling of muscle tissue (3). One RTx patient had a contraindication for the follow-up biopsy, another one refused, and in a third one sampling was not successful. In the HD group, missing samples at baseline were due to unsuccessful sampling (2); reasons for missing follow-up samples were contraindication (1) and renal transplantation (1). In controls, one baseline sample was missing as a result of complications (bleeding) and five follow-up samples were missing due to unsuccessful sampling (4) and contraindication (1). The sampling process did not yield enough tissue in all patients to enable execution of all analyses.

At baseline, $\mathrm{MyHC}$ isoform composition and muscular enzyme activities were not significantly different between the groups (Table 3 ). The proportion of MyHC type I decreased significantly over the training period ( $\mathrm{p}_{\text {time }}<0.001$ ), while the proportion of MyHC type IIa increased $\left(\mathrm{p}_{\text {time }}<0.05\right)$ and the proportion of MyHC type IIx did not change significantly. Changes in $\mathrm{MyHC}$ isoforms were not significantly different between groups (Fig. 1), also not after adjustment for age and sex. HAD activity seemed to increase over time $\left(\mathrm{p}_{\text {time }}=0.052\right.$; Fig. 1), while the activity of GlyP, PFK, and CS did not change significantly (data not shown). Changes in enzyme activities over time were not significantly different between the groups (data not all shown). In RTx patients, no significant interac-

TABLE 3. Skeletal muscle fiber distribution, enzyme activity, and IGF system in the renal transplant (RTx), hemodialysis (HD), and control groups at baseline

\begin{tabular}{|c|c|c|c|c|}
\hline & RTx & HD & Controls & $P$ value $^{a}$ \\
\hline MyHC type I & $31.6 \pm 5.6$ & $35.1 \pm 5.5$ & $34.5 \pm 6.8$ & ns \\
\hline MyHC type IIx & $21.9 \pm 10.4$ & $21.4 \pm 7.3$ & $20.7 \pm 10.7$ & ns \\
\hline \multicolumn{5}{|l|}{ Enzyme capacity (U/mg protein) } \\
\hline Glycogen phosphorylase & $156.9 \pm 78.9$ & $132.7 \pm 100.6$ & $158.4 \pm 66.9$ & ns \\
\hline Citrate synthase & $33.3 \pm 25.9$ & $22.9 \pm 15.8$ & $32.7 \pm 21.1$ & ns \\
\hline 3-hydroxyacyl-CoA-dehydrogenase & $31.3 \pm 16.1$ & $22.7 \pm 16.1$ & $34.7 \pm 22.9$ & ns \\
\hline \multicolumn{5}{|l|}{ Insulin-like growth factor (ng/mg protein) } \\
\hline mIGF-I & $2.3 \pm 1.3$ & $2.9 \pm 3.1$ & $2.4 \pm 1.6$ & ns \\
\hline mIGF-II & $12.1 \pm 7.9$ & $15.5 \pm 10.4$ & $18.3 \pm 9.5$ & ns \\
\hline
\end{tabular}

Data are given as mean \pm SD

${ }^{a}$ Result of two-way ANOVA.

${ }^{b} P<0.05$ versus other groups, corrected for sex. 

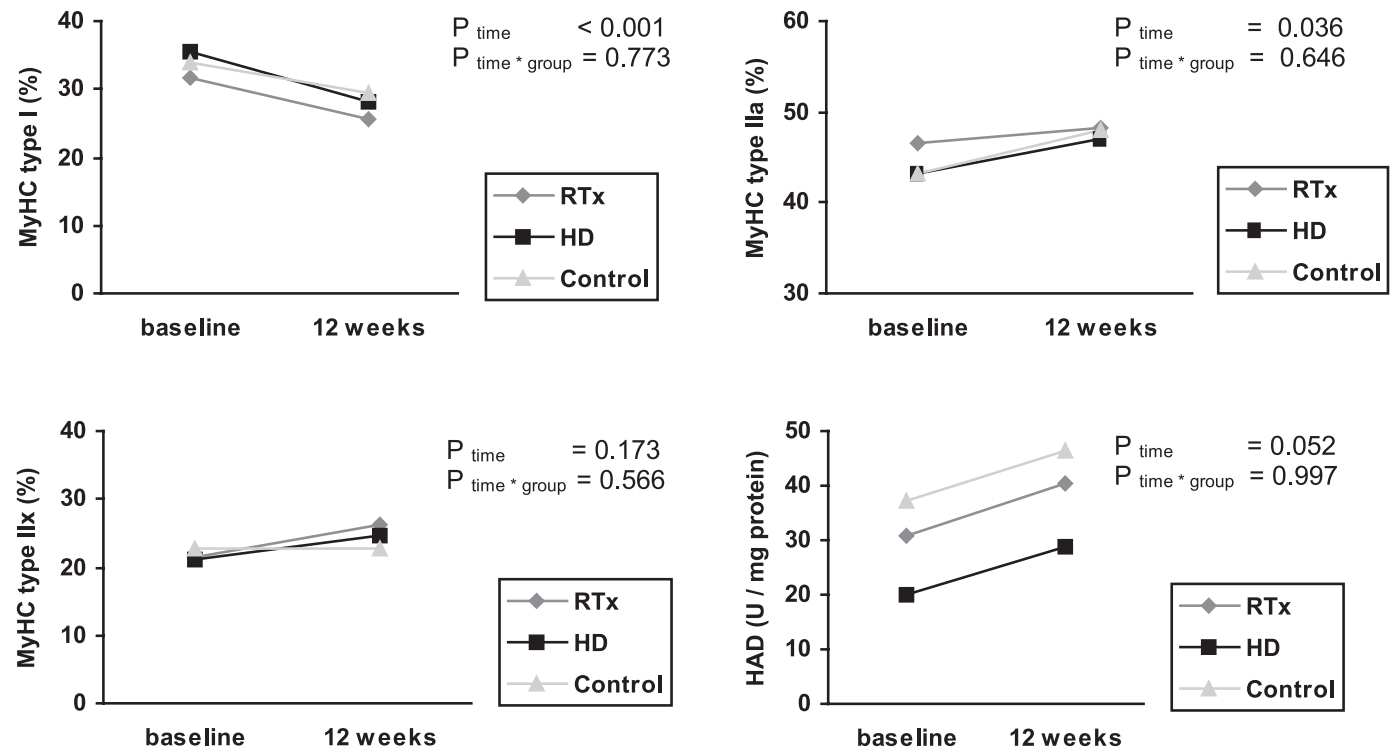

FIGURE 1. Changes in proportion of MyHC and HAD activity in the RTx, HD, and control group from baseline to 12 weeks of training (not adjusted for age and sex). Results of the two-way repeated measures ANOVA. MyHC, myosin heavy chain; HAD, 3-hydroxyacyl-CoA-dehydrogenase.

tion between the use of corticosteroids, or the level of renal function, and the studied parameters was observed.

\section{Muscular IGF System and the Anabolic Response to Training}

Muscle IGF-I, IGF-II, and IGFBP-3 concentrations were not significantly different between the groups at baseline. The fragmentation of mIGFBP-3 in HD patients was significantly increased compared to RTx patients and controls (Table 3).

In the total group of patients and controls, changes in fragmentation of mIGFBP-3 following the intervention were significantly, inversely related to changes in LBM $(r=-0.509$, $P=0.011, \mathrm{n}=24)$. No significant relations were observed between changes scores of the other IGF system components and LBM. In HD patients, changes in mIGF-II, mIGFBP-3, and fragmentation of mIGFBP-3 following the intervention were significantly related to changes in LBM (Fig. 2). In the RTx and control group, no significant relations between changes scores of the IGF system and LBM were found.

\section{DISCUSSION}

In a previous study, we showed that both exercise capacity and muscular strength adjusted for muscle mass were significantly reduced in both HD and RTx patients compared to control subjects, suggesting intrinsic muscular abnormalities in these patient groups (3). However, the present study yielded no differences in skeletal muscle $\mathrm{MyHc}$ isoform composition and oxidative and glycolytic enzyme activity between RTx patients, HD patients, and healthy controls.

Exercise capacity and muscle strength significantly improved over the training period both in renal patients and controls, in agreement with earlier published data $(18,19$, 21-29). In contrast to the hypothesis of the study, improvement in exercise capacity and muscle strength in response to training was not significantly different between the RTx, HD, and control group. This finding underscores the importance of physical inactivity as a contributory factor to reduced exercise capacity and muscle strength both in RTx and HD patients. However, exercise capacity and muscle strength in RTx and HD patients after the training period generally remained lower than the baseline levels of controls. Given the prolonged inactivity in the patients, the duration of the training program might have been too short to accomplish a further increase of exercise capacity and muscle strength.

The absence of differences in MyHC composition reflecting skeletal muscle fiber distribution - between groups of renal patients and controls at baseline are in some contrast to previous studies, although it should be acknowledged that absolute diameter or the number of muscle fibers was not assessed in the present study. Some studies in HD patients reported changes in the ratio of type I to type II fibers and/or atrophy of type I oxidative and type II glycolytic fibers $(14,15,21,40)$, whereas Miro did not find differences in mitochondrial function between HD patients and controls (41). In corticosteroid-treated RTx patients, a shift from type I to type II fibers, atrophy of type I but especially type II fibers, and a reduced oxidative capacity were observed, although fiber type distribution in RTx patients withdrawn from steroids was not different from healthy controls $(4,7,18)$.

In general, prolonged endurance training leads to increased percentages of type I and type IIa fibers accompanied by an increased oxidative capacity resulting in a higher fatigue resistance (42). In the present study, in which both endurance and strength training was performed, the proportion of type I $\mathrm{MyHC}$ isoforms in patients and controls decreased significantly over the training period and the proportion of type IIa $\mathrm{MyHC}$ isoforms increased significantly, without significant differences between the groups. These training-induced changes in $\mathrm{MyHC}$ isoforms indicate that either the number and/or diameter of the type IIa fibers might have increased or 

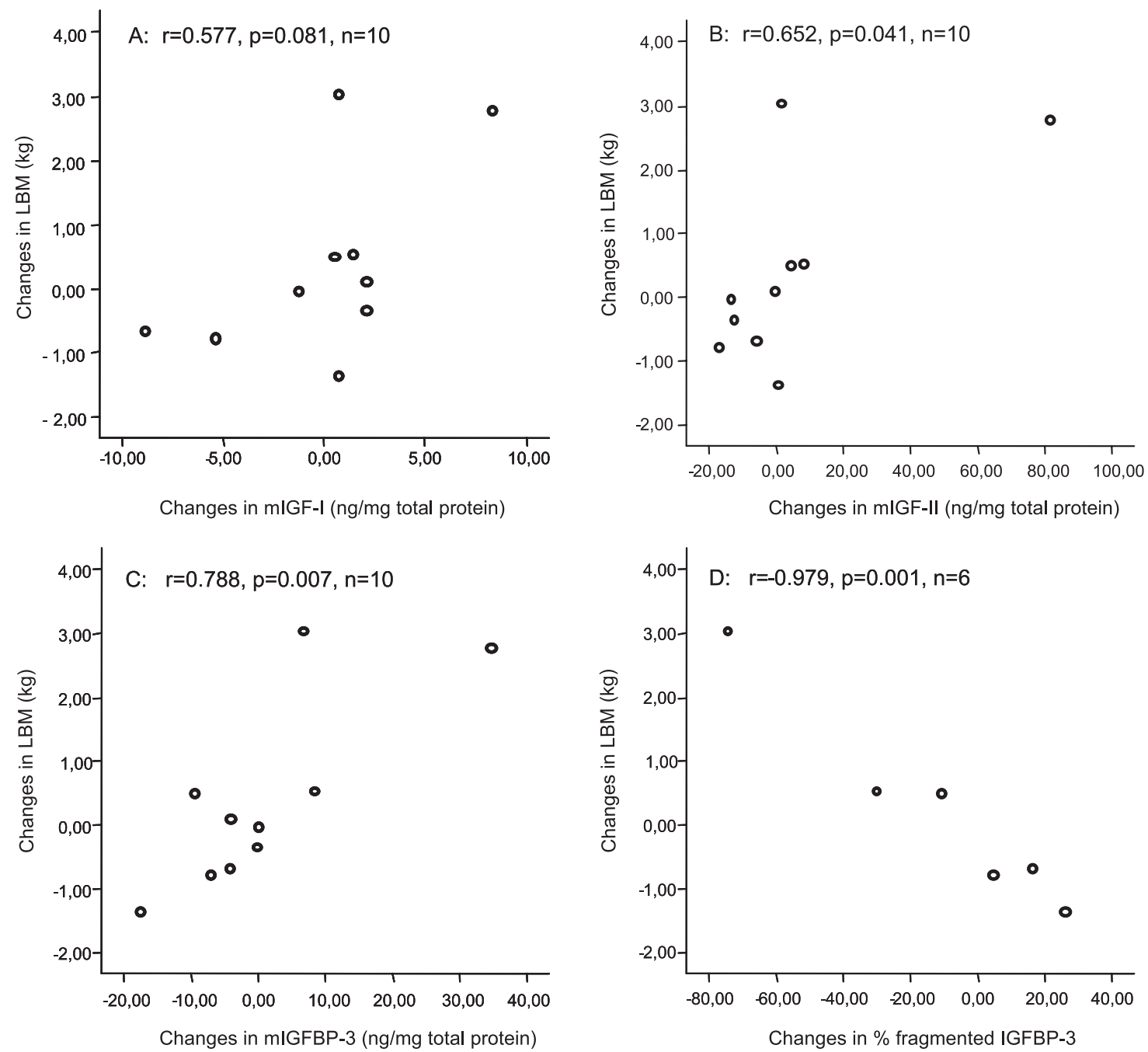

FIGURE 2. Scatter plots of the change scores in the components of the IGF system and changes in LBM following the exercise intervention in the HD patients. LBM, lean body mass; mIGF, muscle insulin-like growth factor; mIGFBP, muscle insulin-like growth factor binding protein; \% fragmented, percentage of $30 \mathrm{kDa}$ fragment by Western immunoblotting.

that the number and/or thickness of type I fibers might have decreased. Due to the composition of the training program, we believe the latter hypothesis is less likely.

In the present study, we assessed the metabolic profile by activity measurements of oxidative and glycolytic enzymes. Glycogen phosphorylase and phosphofructokinase are involved in the glycolytic metabolism, 3-hydroxyacylCoA-dehydrogenase (HAD) is an important enzyme in the oxidation of fatty acids, and citrate synthase is a key enzyme in the tricarboxylic acid cycle. At baseline, no differences in oxidative or glycolytic enzyme activity were observed between RTx patients, HD patients, and controls. Earlier findings showed a reduced skeletal muscle oxidative capacity in RTx and HD patients compared to healthy controls $(14,18,20)$. The results of this study suggest that any perturbations in muscle oxidative capacity in RTx and HD patients are not due to abnormalities in muscular enzyme activity.

The training intervention appeared to increase HAD activity in patients and controls, without differences between the groups. An improvement in HAD activity may be of clinical importance, as a reduced capacity for fatty acid oxidation in skeletal muscle seems to play a crucial role in the etiology of insulin resistance $(43,44)$, which is common in renal patients (45).

The change in LBM was significantly larger in controls compared to the HD and RTx patients. Painter et al. (22) did not find changes in body composition in RTx patients after twelve months of cardiovascular exercise training. MacDonald did not observe changes in LBM of HD patients after 3 months of intensive cycle training either (29), although other studies, which primarily focused on resistance training, have shown impressive effects on muscular atrophy in renal patients $(5,46,47)$. Our training program consisted of both endurance and strength training. The anabolic stimulus necessary to counteract the catabolic effects associated with renal failure might have been too mild. Moreover, the absolute stimulus was lower in the patient groups than in controls, due to the standardized training program that was based on the results of the function tests at baseline.

Although LBM in the whole group did not increase significantly in HD and RTx patients, training-induced changes in LBM were related to mIGF-II and mIGFBP-3, es- 
pecially in the HD group. The exact mechanism of this relationship is unclear, but muscle cell lines are known to produce IGFBP-3, which can have both mediating effects on mIGFs (increasing IGF half life and potentiating IGF action), and also independent effects on protein synthesis (46). Although focus has traditionally been on IGF-I, IGF-II also plays an important role in physiology (47). IGF-II is present in excess of IGF-I in various fluids and tissues (48), it can interact with the IGF-I receptor (49), decreased IGF-II can reduce IGF-I bioavailability (50) and, due to its greater half life than IGF-I, it provides a longerterm reserve IGF pool (48).

Of interest, mIGF-I and II levels were not significantly different between the three groups. This is in contrast to the HD patients studied by MacDonald et al., who were significantly more muscle wasted compared to our patients (12). Wang et al. showed increased mIGF-I levels in HD patients who were not muscle wasted, despite a reduction in muscular IGF-I and II mRNA levels (13). We observed increased fragmentation of both muscular and serum IGFBP-3 in HD patients compared to controls. Increased fragmentation of IGFBP-3 has been shown previously in uremic serum (12), but not yet in muscle. Although the causes and significance of this finding are not clear, fragmentation has been hypothesized to both enhance (51) and inhibit IGF action (52). Further research on the muscular IGF system is needed to provide adequate explanation for these findings.

Although it was not the primary scope of the study, exercise training improved quality of life (SF-36 questionnaire) in the renal patients, in particular the scores related to physical functioning (data not shown) $(22,27,39,53,54)$. In RTx patients, no relationship between physical functioning scores and outcome has yet been established. In HD patients, the SF-36 Physical Component Scale is a predictor of outcome (55-57).

In our study, only clinically stable RTx and HD patients without severe comorbidity and able to perform maximal exercise testing were included. This limits the generalizability of the study. Other limitations of our study are the unequal numbers of males and females in the HD group (solved by correcting for sex in the analyses) and the wide range in posttransplantation time and time since starting HD. Regarding the last, however, no relationships were observed between these parameters and baseline levels of studied parameters or the response to training. Although we included RTx patients with and without corticosteroid treatment, interaction analysis showed no effect of corticosteroid treatment on studied parameters in the present study.

Summarizing, although skeletal muscle strength was significantly reduced both in RTx and HD patients compared to controls, no differences in muscle $\mathrm{MyHC}$ isoform composition, enzyme activity, and IGF-I and II concentrations were observed between these three groups. Exercise training has comparable beneficial effects on both functional and intrinsic muscular parameters in RTx patients, HD patients, and controls. Especially in HD patients, the anabolic response to training is related to changes in the muscle IGF system.

\section{REFERENCES}

1. Painter P. Physical functioning in end-stage renal disease patients: Update 2005. Hemodial Int 2005; 9: 218.
2. Painter P, Hanson P, Messer-Rehak D, et al. Exercise tolerance changes following renal transplantation. Am J Kidney Dis 1987; 10: 452.

3. van den Ham EC, Kooman JP, Schols AM, et al. Similarities in skeletal muscle strength and exercise capacity between renal transplant and hemodialysis patients. Am J Transplant 2005; 5: 1957.

4. Horber FF, Hoppeler H, Herren D, et al. Altered skeletal muscle ultrastructure in renal transplant patients on prednisone. Kidney Int 1986; 30: 411 .

5. Horber FF, Scheidegger JR, Grunig BE, Frey FJ. Thigh muscle mass and function in patients treated with glucocorticoids. Eur JClin Invest 1985; 15: 302 .

6. LaPier TK. Glucocorticoid-induced muscle atrophy. The role of exercise in treatment and prevention. J Cardiopulm Rehabil 1997; 17: 76.

7. Topp KS, Painter PL, Walcott S, et al. Alterations in skeletal muscle structure are minimized with steroid withdrawal after renal transplantation. Transplantation 2003; 76: 667.

8. Reid MB, Li YP. Cytokines and oxidative signalling in skeletal muscle. Acta Physiol Scand 2001; 171: 225.

9. Li YP, Reid MB. Effect of tumor necrosis factor-alpha on skeletal muscle metabolism. Curr Opin Rheumatol 2001; 13: 483.

10. Buck M, Chojkier M. Muscle wasting and dedifferentiation induced by oxidative stress in a murine model of cachexia is prevented by inhibitors of nitric oxide synthesis and antioxidants. Embo J 1996; 15: 1753.

11. Adams GR. Invited Review: Autocrine/paracrine IGF-I and skeletal muscle adaptation. J Appl Physiol 2002; 93: 1159.

12. Macdonald JH, Phanish MK, Marcora SM, et al. Muscle insulin-like growth factor status, body composition, and functional capacity in hemodialysis patients. J Ren Nutr 2004; 14: 248.

13. Wang H, Casaburi R, Taylor WE, et al. Skeletal muscle mRNA for IGF-IEa, IGF-II, and IGF-I receptor is decreased in sedentary chronic hemodialysis patients. Kidney Int 2005; 68: 352.

14. Diesel W, Emms M, Knight BK, et al. Morphologic features of the myopathy associated with chronic renal failure. Am J Kidney Dis 1993; 22: 677 .

15. Fahal IH, Bell GM, Bone JM, Edwards RH. Physiological abnormalities of skeletal muscle in dialysis patients. Nephrol Dial Transplant 1997; 12: 119.

16. Franssen FM, Wouters EF, Schols AM. The contribution of starvation, deconditioning and ageing to the observed alterations in peripheral skeletal muscle in chronic organ diseases. Clin Nutr 2002; 21 : 1 .

17. Gosker HR, Wouters EF, van der Vusse GJ, Schols AM. Skeletal muscle dysfunction in chronic obstructive pulmonary disease and chronic heart failure: Underlying mechanisms and therapy perspectives. Am J Clin Nutr 2000; 71: 1033.

18. Kempeneers G, Noakes TD, van Zyl-Smit R, et al. Skeletal muscle limits the exercise tolerance of renal transplant recipients: effects of a graded exercise training program. Am J Kidney Dis 1990; 16: 57.

19. Diesel W, Noakes TD, Swanepoel C, Lambert M. Isokinetic muscle strength predicts maximum exercise tolerance in renal patients on chronic hemodialysis. Am J Kidney Dis 1990; 16: 109.

20. Moore GE, Bertocci LA, Painter PL. 31P-magnetic resonance spectroscopy assessment of subnormal oxidative metabolism in skeletal muscle of renal failure patients. J Clin Invest 1993; 91: 420.

21. Kouidi E, Albani M, Natsis K, et al. The effects of exercise training on muscle atrophy in haemodialysis patients. Nephrol Dial Transplant 1998; 13: 685.

22. Painter PL, Hector L, Ray K, et al. A randomized trial of exercise training after renal transplantation. Transplantation 2002; 74: 42.

23. Painter PL, Nelson-Worel JN, Hill MM, et al. Effects of exercise training during hemodialysis. Nephron 1986; 43: 87.

24. Koufaki P, Mercer TH, Naish PF. Effects of exercise training on aerobic and functional capacity of end-stage renal disease patients. Clin Physiol Funct Imaging 2002; 22: 115.

25. Headley S, Germain M, Mailloux P, et al. Resistance training improves strength and functional measures in patients with end-stage renal disease. Am J Kidney Dis 2002; 40: 355.

26. DePaul V, Moreland J, Eager T, Clase CM. The effectiveness of aerobic and muscle strength training in patients receiving hemodialysis and EPO: A randomized controlled trial. Am J Kidney Dis 2002; 40: 1219.

27. van Vilsteren MC, de Greef MH, Huisman RM. The effects of a low-tomoderate intensity pre-conditioning exercise programme linked with exercise counselling for sedentary haemodialysis patients in The Netherlands: Results of a randomized clinical trial. Nephrol Dial Transplant 2005; 20: 141. 
28. Kouidi E, Grekas D, Deligiannis A, Tourkantonis A. Outcomes of longterm exercise training in dialysis patients: Comparison of two training programs. Clin Nephrol 2004; 61(Suppl 1): S31.

29. Macdonald JH, Marcora SM, Jibani M, et al. Intradialytic exercise as anabolic therapy in haemodialysis patients - a pilot study. Clin Physiol Funct Imaging 2005; 25: 113.

30. Mehls O, Himmele R, Homme M, et al. The interaction of glucocorticoids with the growth hormone-insulin-like growth factor axis and its effects on growth plate chondrocytes and bone cells. J Pediatr Endocrinol Metab 2001; 14(Suppl 6): 1475.

31. Rothkrantz-Kos S, Bekers O, Gubbels A, et al. Evaluation of two new high-sensitivity methods for C-reactive protein. Ann Clin Biochem 2003; 40(Pt 4): 398.

32. Bergstrom L. Muscle electrolytes in man. Determination by neutron activation analysis on needle biopsy specimens. A study on normal subjects, kidney patients, and patients with chronic diarrhea. Scand J Clin Lab Invest 1962; 68: 7.

33. Schreiber WE, Bowling S. An automated assay of glycogen phosphorylase in the direction of phosphorolysis. Ann Clin Biochem 1990; 27(Pt 2): 129.

34. Ling KH, Pastkau V, Marcus F, Lardy HA. Phosphofructokinase. I Skeletal muscle. Meth Enzymol 1966; 9: 425.

35. Shephard D, Garland PB. Citrate synthase from rat liver. Meth Enzymo 1969; 13: 11 .

36. Bergmeyer HU, Gawehn K, Grassl M. 3-Hydroxyl-CoA dehydrogenase. In: Bergmeyer HU, ed. Methods of Enzymatic Analysis. Weinheim: Verlag Chemie GmbH, 1974: 474.

37. Talmadge RJ, Roy RR. Electrophoretic separation of rat skeletal muscle myosin heavy-chain isoforms. J Appl Physiol 1993; 75: 2337.

38. Gosker HR, Schrauwen P, Broekhuizen R, et al. Exercise training restores uncoupling protein-3 content in limb muscles of patients with chronic obstructive pulmonary disease. Am J Physiol Endocrinol Metab 2006; 290: E976.

39. Painter P, Carlson L, Carey S, et al. Physical functioning and healthrelated quality-of-life changes with exercise training in hemodialysis patients. Am J Kidney Dis 2000; 35: 482.

40. Johansen KL, Shubert T, Doyle J, et al. Muscle atrophy in patients receiving hemodialysis: Effects on muscle strength, muscle quality, and physical function. Kidney Int 2003; 63: 291.

41. Miro O, Marrades RM, Roca J, et al. Skeletal muscle mitochondrial function is preserved in young patients with chronic renal failure. Am J Kidney Dis 2002; 39: 1025.

42. McComas AJ. Skeletal muscle: form and function. Champaign: Human Kinetics; 1996.
43. Kelley DE, Goodpaster B, Wing RR, Simoneau JA. Skeletal muscle fatty acid metabolism in association with insulin resistance, obesity, and weight loss. Am J Physiol 1999; 277(6 Pt 1): E1130.

44. Kim JY, Hickner RC, Cortright RL, et al. Lipid oxidation is reduced in obese human skeletal muscle. Am J Physiol Endocrinol Metab 2000; 279: E1039.

45. Fliser D, Kielstein JT, Menne J. Insulin resistance and renal disease. Contrib Nephrol 2006; 151: 203.

46. Horber FF, Scheidegger JR, Grunig BE, Frey FJ. Evidence that prednisoneinduced myopathy is reversed by physical training. J Clin Endocrinol Metab 1985; 61: 83.

47. Castaneda C, Gordon PL, Uhlin KL, et al. Resistance training to counteract the catabolism of a low-protein diet in patients with chronic renal insufficiency. A randomized, controlled trial. Ann Intern Med 2001; 135: 965

48. Rajaram S, Baylink DJ, Mohan S. Insulin-like growth factor-binding proteins in serum and other biological fluids: Regulation and functions. Endocr Rev 1997; 18: 801.

49. Jain S, Golde DW, Bailey R, Geffner ME. Insulin-like growth factor-I resistance. Endocr Rev 1998; 19: 625.

50. Canalis E. Inhibitory actions of glucocorticoids on skeletal growth. Is local insulin-like growth factor I to blame? Endocrinology 1998; 139: 3041.

51. Crown AL, Cottle K, Lightman SL, et al. What is the role of the insulinlike growth factor system in the pathophysiology of cancer cachexia, and how is it regulated? Clin Endocrinol (Oxf) 2002; 56: 723.

52. Jehle PM, Ostertag A, Schulten K, et al. Insulin-like growth factor system components in hyperparathyroidism and renal osteodystrophy. Kidney Int 2000; 57: 423.

53. Levendoglu F, Altintepe L, Okudan N, et al. A twelve week exercise program improves the psychological status, quality of life and work capacity in hemodialysis patients. J Nephrol 2004; 17: 826

54. Painter P, Carlson L, Carey S, et al. Low-functioning hemodialysis patients improve with exercise training. Am J Kidney Dis 2000; 36: 600.

55. DeOreo PB. Hemodialysis patient-assessed functional health status predicts continued survival, hospitalization, and dialysis-attendance compliance. Am J Kidney Dis 1997; 30: 204.

56. Lowrie EG, Curtin RB, LePain N, Schatell D. Medical outcomes study short form-36: A consistent and powerful predictor of morbidity and mortality in dialysis patients. Am J Kidney Dis 2003; 41(6): 1286.

57. Knight EL, Ofsthun N, Teng M, et al. The association between mental health, physical function, and hemodialysis mortality. Kidney Int 2003; 63: 1843 . 